\title{
Speculative Bubbles in the Near Future? Not Unlikely Indeed
}

\author{
Dott. Giovanni Antonio COSSIGA \\ Correspondence: Dott. Giovanni Antonio COSSIGA, Presidente Collegio Sindaci Policlinico Umberto1, Università \\ Sapienza, Roma, Italy.
}

Received: December 7, 2017

Accepted: December 25, 2017

Available online: January 4, 2018

doi:10.11114/aef.v5i2.2913

URL: https://doi.org/10.11114/aef.v5i2.2913

\begin{abstract}
In the near future, the world economy would be crossed by a new wave of speculative crisis? To answer this question, we can have a look at the economy performance during the speculative bubble formation and the 2008-2009 financial crisis. Our intention is to verify whether the troubles of the last decade speculative crisis may recur again in the coming years. Particularly, we want to look at the price trend, which may be the forerunner of new speculative waves, if and when prices would show a prolonged deflation trend. At the same time, we'll look at the growth profile in the economy which, during the speculative phase, is showing an ambiguous measured trend. This behaviour of the main variables, low inflation and almost regular growth, is for operators and families a sort of mirage about the economy outlook. A deceptive mirage, however, that gives the feeling that the speculative wave is a sort of catalyst for a long growth phase. Actually, the economic system seems to follow the physical laws of the material world, according to a growth trend compatible with environmental resources. A system derailing from this path becomes unstable and sooner or later must return to the equilibrium natural state. The speculative wave can be defined as an extreme natural mechanism, put in place by the system to get out of the accumulated errors. If this correction is done, the wave of speculative tensions ends with the return of the economy within the compatible growth virtuous course. Well, there are symptoms that the natural correction of economic systems is not complete, despite the strength and intensity of the 2008-2009 crisis. Therefore, we can expect that a new speculation wave could be hidden in our next future.
\end{abstract}

Keywords: speculative bubbles, speculative crisis, instable economy, natural correction, deflation

\section{Introduction}

So, we have an unanswered question, which can be proposed as follows: the business community in general can expect in the future a succession of speculative bubbles? After the traumatic events and troubles left by repeated speculation waves, especially in the northern area, are we facing a spiral loop of new speculative waves? Moreover, why the trauma left on the economy by these past troubles have not yet exhausted their devastating impact? Would maybe still exist some burning embers ready to re-emerge with a spectacular fire of successive speculative bubble waves, which could affect the continental areas, in a disorderly and timeless way?

In a more or less near future, some adverse financial reflections could still affect our economies. After twenty years of inflation and disinflation in the 70's and 80's, at the beginning of the new century we entered in a period of prolonged deflation in the world economy. Could be this deflation trend a precursor of speculative tensions? These speculative pressure loops are recurring and seem to move as spirals, always followed by financial crises. As a common feature throughout the instability period, they show a persistent tendency to the deflation within economic systems.

The mechanism seems to be the same and is tending to be repeated. A cycle of speculative bubbles, followed by a financial crisis, is strangely announced by a relatively brief period (just few years) of relative calm. In the whole cycle so outlined - a period of calm, speculation in acceleration, crisis - the basic characteristic is the tendency to deflation, quite insensitive to monetary policies supporting the economy. Also, the economy is showing a fundamental fragility, even in contradiction with other significant variables that may have an almost satisfactory performance.

Somewhat unexpected and unsuspected, a new speculative movement may be inserted, generally involving activity sectors other than those affected by a previous bubble. It is quite strange that, despite the relative proximity of the previous episode, both the market and the operators seem to have no memory of the recent past and therefore are attracted by the speculative game without assessing the growing risk. If the previous episode did not leave deep traces on the economy, the next one could be more aggressive as speculative strength and financial crisis depth. The sequence can continue then, after a calm period. 
The reason for this re-emerging speculative strength, with cycles or recurrent spiral loops, is obviously to be found in the instability state of economies. A condition that could remain unsolved after a price trouble affecting a specific sector of the economy and therefore may continue to be repeated, together with its tendency to deflation if the economy conditions remain unbalanced.

The theme of this discussion is the research - wherever possible - of the reasons for the economic systems' tendency to deflation over the past two decades, showing a strong persistence such as the inflation-disinflation affair during the seventies and eighties. It's clear that the strategies put in place to remove the cumbersome, stubborn deflation monster with a transitory effectiveness - would clearly come out from the economy disorder.

\subsection{The Distinctive Marks of a Speculative Crisis}

The most obvious mark left by an unstable economic system feeding a bubble and a financial crisis in pectore, is impressed on the pricing system, the mechanism through which an economic system seems to communicate explicitly with enterprises and operators. Prices and their movement are an immediate precursor directly perceivable about the economy state. Iinflation and deflation are essentially a sort of continuous and immediate information - in a non-colloquial but comprehensible way - about the unstable state of the economic system.

We can roughly say that inside a system with a speculative bubble, the downward price pressure is an unavoidable signal that the economic system instability is linked to the indebtedness unsustainability: in other words, a debt bubble inconsistent with the economy state. The speculative emphasis is synonymous of a growing abuse of indebtedness, in contrast with the growth potential of the real economy.

Another potential mark left by instability, in the case of a speculative bubble formation, is impressed on the same field of the real economy. The strong effervescence of one or more sectors of the economy doesn't seem to be able to give strength to a general growth of the economy. In fact, during those phases of improper emphasis, the development engine is calm, if not even weak. The reason for this apparent discontinuity between a bubble emphasis and a retained development, is fully plausible: the system is unstable and badly working, with some wheels moving too fast while the others are slowing down.

We must note that the portion created inside the economy by the improper bubble whirl is virtual, then precarious and therefore destined to be swept away by the crisis in pectore. If we consider the destiny of this part of the unstable economy, we should conclude that even the real growth in the economy becomes essentially null or negative. In other terms, the trend of deflation rates is indirectly reflected in a parallel sequence of GDP, which is poor or negative, and only virtually growing.

The unambiguous and strong relationship between the two variables, GDP and Inflation, is perhaps the Arianne's thread to go out from the unusual whirl of recurrent crises following all speculative bubbles. (Cossiga, 2017) In the case of economic instability, the principal phenomenon occurring and easily detectable is represented by the relationship between the variables, GDP and Inflation. In other words, the drift of the economy become unstable for the natural correction, has a depressing effect on the potential growth of the stable economic system.

In case of inflation, this decline is marked by a cyclical trend, having waves with a maximum (recovery) and a minimum (recession) and which are repeated and degrading. This degradation is reported by the progressive decline of the recovery phase and a consequent expansion of the recessive phase. This trend through cycles, degrading the quality of economic development, is generally repeated on the front of prices with a short delay (two to three quarters). The price system is moving with an open symmetry, though delayed, with the cyclical trend of the economy.

The excitement of the economy and price cycles is high in case of inflation, and therefore the instability persistence is reflected in a gradual expansion of the oscillations. When inflation reaches and exceeds $20-30 \%$, the two variables, GDP and Inflation, are maintaining a characteristic bond, although the recovery cycle is fading, while the economy negative cycle is accentuated and extended. In parallel, the cyclical price trend is tending to oscillate in correlation with the cyclical trend. The price fluctuation moves around an axis assuming, towards the abscissa, a specific inclination, which depends on the duration and instability degree of the economic system. 


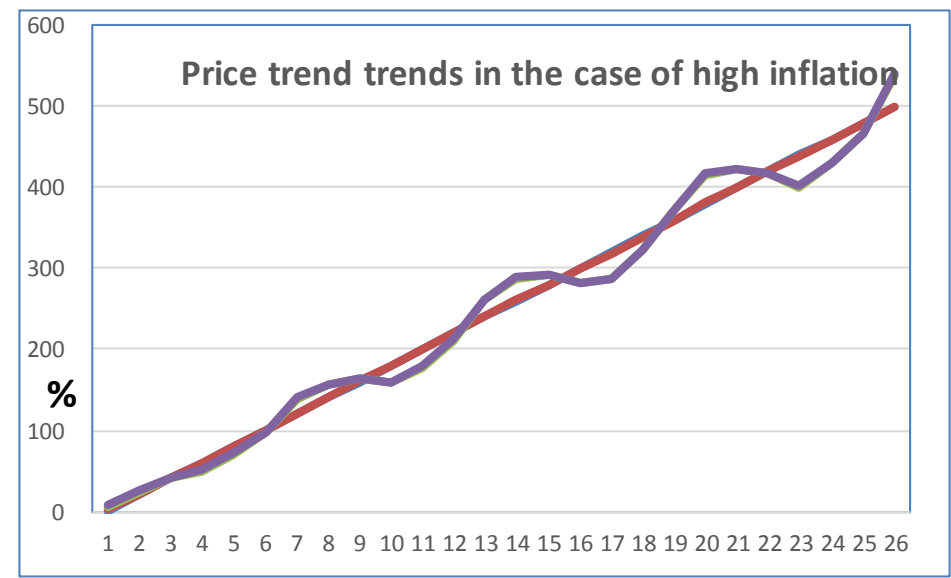

Figure 1. Price trend-line in case of high inflation*

* On the ordinate axis, the inflation growing trend. On the abscissa axis, a hypothetical temporal trend

\section{Method}

\subsection{The Apparent Dystonia of the Two Variables}

In the case of deflation or tendency to deflation, the partnership of the two variables, GDP - Inflation, is always very strong as shown in a previous published work. However, the evolution of the two variables during the speculative bubble formation phase is showing an apparent inverse relationship. Slow and progressively declining inflation, while GDP remains in positive position, although the growth is moderately low despite the euphoria in some sectors of the economy.

This apparent dystonia of the two variables, essential for the assessment of an economy health, shouldn't mislead the observer. Indeed, we should be worrying about the abnormality of falling prices, slow but progressive, and about the economic growth usually limited within $2 \%$ per annum, during the phase of bubble formation. In such a false context, the unfavourable side emerges from a significant confrontation with the behaviour of a healthy economy. Under stable conditions, the economy growth can be contained and the progression of $2 \%$ per annum is fully acceptable, notwithstanding the prices must remain neutral with respect to the economic events.

Prices tending to a prolonged decline, therefore, could be an unacceptable condition within a healthy economy. Even more, because between the two variables a link has been created, only apparently inverted, but direct indeed if we do not consider the false context of the speculative economy.

The inflation factor, which is showing a steady and slow decline during the bubble formation, certainly has been underestimated during the recent instability cases with speculative bubble. Underestimation is probably linked to the growth of the economy, which was only apparently healthy. Moreover, during the bubble formation phase, the excitation created within the markets, particularly the financial ones, is giving motivation for an employment growth pushed not only by objective factors, but also by the perspective of the unlimited growth mirage, which is at the origin of the speculation run.

This may be one of the reasons for the occupational sudden fall with the arrival of the financial crisis, so ending the market unreasonable running. Undoubtedly, during the bubble formation the economy seems to draw a highly misleading scenario. The economy state seems apparently serene, with the growth within the limits, the unemployment even touching the minimal levels, the inflation flat or almost zeroed. Yet the economy it's in a state of high instability, a state attained when for a long time, implicit or explicit information on the economy state have been neglected or mislead by institutions, companies and operators.

In the present situation, the sequential series of speculative waves during the recent past (the long run of the so-called dot.com, the oil intense acceleration and the 2008-2009 deep crisis after the Real Estate speculation) is firmly imprinted in the collective memory. And therefore, it seems so difficult to believe that may still exist the unusual mirage of unrestricted growth, which at the time led astray the risk assessment.

We could believe that the formation of new bubbles in the future wouldn't find the same slippery ground that in the recent past has favoured the formation and the outbreak of the speculative intemperance, if only for the experience gained through the recent events. Anyway, it's quite singular that a speculative bubble long series emerged in our century, when the unstoppable exuberance of the 1920s as well the severe financial and monetary economy crisis of the 1930s were well known. 
The most impressive phenomenon is therefore the surprising repetition of speculative waves that we can only partially justify, taking in account the relative tranquillity of main variables, beginning with the economy cautious growth and with the employment increase. Signals that may clash however, given the effervescence of some economy sectors and even the sappy atmosphere during the speculative wave development which should generate some questions. And this should induce to have a closer look at the phenomenon evolution.

Often the devil is in the details, indeed. An analysis of the GDP profile with quarterly data can in fact highlight an item not to be underestimated. While at an annual level, the economic growth is showing a calm though acceptable trend, the quarterly trend shows instead an intermittent movement. A mini cycle going from one falling quarter to the next growing, so that in the year average the economy is quietly growing.

Let's examine below, to better observe the phenomenon, the profiles of the GDP cycle in the USA, UK, Denmark and Greece, over the years when the speculative crisis developed. For all, the observation period covers the years 2004-2007. As we can see from Figure 2, this short cycle ends in about a year and continues with this rhythm until the bubble outbreak.

The fluctuation tension is wider and more detailed in the Graph regarding Denmark, to testify the degree of probable instability investing the economic system. It should be noted, however, that the phenomenon of the mini cycles in the GDP quarterly profile - reflected also on the inflation cycle - is a specific characteristic of all unstable systems. A feature, therefore, that could be useful to assess the economy trend outside the normal development course, compatible with the environment.

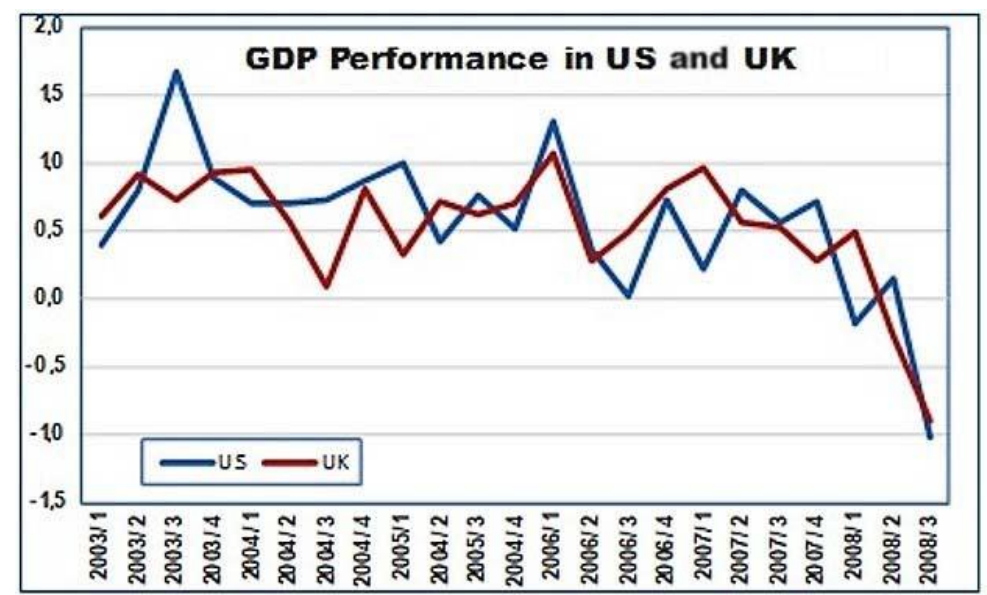

Figure 2/a. GDP trend in US and UK during the speculative bubble formation in 2004-2007

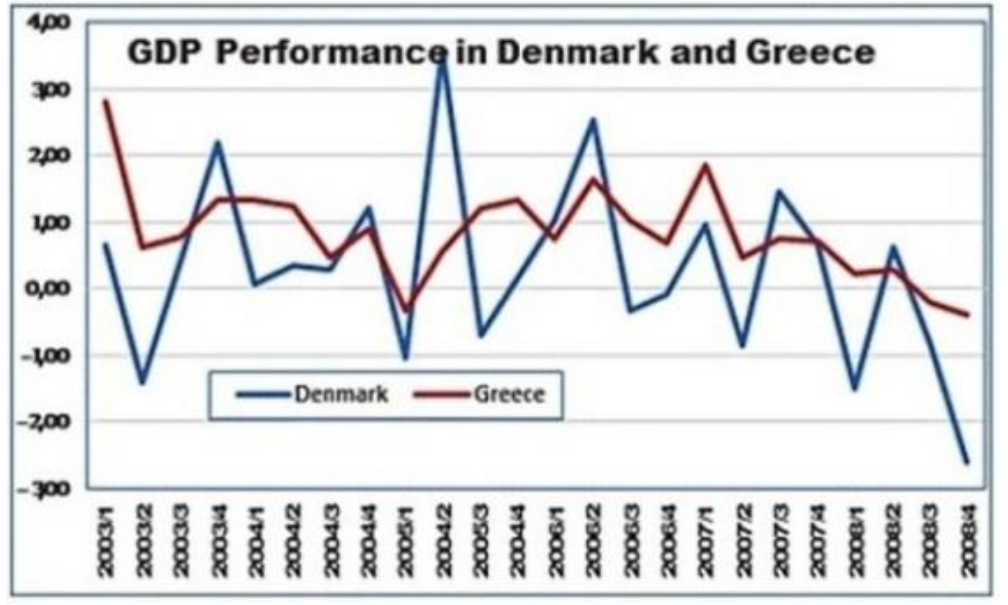

Figure 2/b. GDP trend in Denmark and Greece during the speculative bubble formation in 2004-2007

Source: Elaboration on OECD.Stat

Going beyond the apparent normality and quiet ambiguity of some macro variables during the development of a speculative bubble, we can observe the deep alteration of the system, which is well represented by the obsessive trend of the GDP mini-cycle. In other words, the economic system seems to mask intentionally the altered state, almost 
injecting into the operators a sort of relaxing message about the economy state. Nevertheless just a minimally deeper analysis reveals the rhythmic convulsions fed by the speculative process in action.

Once the process leading to speculative bubble has started, the process seems irreversible. It is reasonable to argue that there is some implicit determination inside the economic system towards the "final catharsis" of the financial crisis, perceived as a liberating process which can lead back the altered system again into the normality. This is a sort of singularity that seems useful to study, in view of a possible intervention for the speculation control or, at least, to check the after-bubble damages.

\subsection{Can the Imprints Left by the Bubble Be Misleading?}

So, the traces left by the speculative process on the main macro-variable profiles seem quite elusive, as if the economic system would show an innate inviolable tendency to go on until the speculative bubble explosion threshold. So, starting a heavy financial crisis penalizing all the economy components, and so extending the social inequality for the unemployment prolonged increase.

How to justify this singular behaviour of the unstable systems, which seems to be against every natural law that allowed the humankind development together with its economic and social relationships. However, apart from some ethical considerations about the evolution of relationships in human societies, it's clear how the development of societies over time is anyway moving towards forms of increasing respect for the environment. This tendency toward a development consistent with the respect for the planet health, must be part of a complex mechanism of action and feedback between human societies development and planet life.

In other words, the cultural, social and economic growth of humanity and its acceleration in modern times, despite the adversity due to natural factors or human errors, can only be explained if we admit that the development process, not only economic, is tending to follow over time a way of general stability. A deviation from the normal course of economic development, for human error or otherwise, therefore should meet a course adjustment, that at some point would bring back the system on the path of a stable and compatible development. This natural tendency of the systems towards a compatible development reasonably should come from the principle of the natural system conservation, which anyway is closely linked to the humankind survival.

There is no doubt that the development of the economies can have an increasing effect on the overall health of the planet, Therefore, we believe that over time is growing the need for a continuous coherence between the economy state and the planet condition. Coherence more necessary than ever, because the influence potentials over the nature are growing in relation to the humankind and technology development. Consistently, the stability requirement for the economies (stability understood as the measure of a good relationship between economy and nature) becomes over time more and more imperative.

On this basis, we can ask ourselves if the characteristic carelessness to the risk hanging over institutions, professional operators and families during the bubble formation, was intended exclusively to lead the altered system to its pay-off. So in this way would take place a forced atonement and, through this, the gradual return of the system to the balance between economy development and environment state.

Certainly, the repetitiveness of the "bubbles" phenomenon seems to support the idea that it's a strategy continually renewed to fulfil an irrevocable obligation that is to bring the economy back on the path of stability and compatibility with the planet health. Try to consider the "tulips" bubble in the Netherlands of the eighteenth century. Not to be compared with the 1900s and 2000s crises, anyway the irrevocable process leading to the "tulip mania" outbreak appears quite similar to the doped mechanism responsible in recent years for the bubble explosion and for the severe financial crisis. A sort of necessary penalty offered to atone for the breakage of the relationship between economy and nature.

This is suggesting that the singular lethargy demonstrated by operators and families facing the bubble formation with its obvious irrationality, could be part of a strategy. A sort of disease to push the phenomenon to reach its climax, so starting the altered system correction, though causing enormous damages on the economy and on the country's social fabric. Even these very serious damages caused by the correction, are anyway irrelevant when compared with the catastrophic consequences of an irreversible damage to the economic system and to the whole planet.

\subsection{The Phenomenon of the Speculation Unstoppable Run to the Ultimate End}

The experience seems to suggest that the formation phase of a speculative bubble is often a phenomenon prolonged over time, often for years. A long interval, yet doesn't seem to leave any space for a remedial action of institutions and operators, to try to start a progressive attenuation of the speculative pressure. In other words, once a speculative bubble formation has begun, experience seems to show that the speculative process can continue until its inevitable conclusion. Based on experience, would not be admissible or even possible a control manoeuvre to contain the phenomenon 
development. It's quite worrying to note that if we are inside a speculative bubble, we can have only the realistic expectation of a near financial crisis. (Krugman, 2009)

The inevitability of the severe epilogue of speculative game, is therefore the imminent risk that we can expect from an economy deviating long and without corrective actions from the stability path. This expected and unavoidable outcome seems to suggest that the economic system anyway has its own capability to control the altered state of the economy health. When comes out on the economy scenario, the speculation spectrum - though irrational - is like a loaded weapon ready to fire, to impose the correction path and the return to compatible and stable growth. Then, when the speculative run is started, the "drift" towards the financial crisis seems irrevocable.

The phenomenon, on the other hand, is repetitive. The speculation-crisis sequence over time has been repeated unchanged in its proceed, although with different intensities and actors involved, to finally embrace the entire world economy in the recent 2008-2009 crisis. These features, repetition over time and mandatory nature of the speculation-crisis course, seem to confirm the existence of an obligation about economic growth. In the medium-long run, the economy must follow a stable growth path, therefore compatible with the natural environment. Nevertheless, in case of deviation from the natural course, some tolerance is possible but for a limited period of time, and beyond this the natural correction process becomes unavoidable. The correction is always accompanied by a monetary proof easy-to-understand, inflation or deflation, so that the weaknesses in the economy conduction are perceived erga omnes.

However, the phenomenon of the speculation unstoppable run to the ultimate end, just seems to confirm the principle of the stability tendency within the development of economic systems. It can be assumed that taking the "no return" way would mean that the intervention margins are exhausted and therefore the interruption of the speculation-crisis process would conflict with the purpose of the altered system return to stability. In other words, wherever the run should be interrupted on the speculation secondary track, it would be distorted the target of a return on the compatible growth path, because of the heavy correction

Now, the system intrinsic obligation towards the compatible development convergence and the rigidity of the speculation-crisis course within this compulsory convergence, are leading us to the question on the potential consequences of the economic and monetary policy measures adopted during the post- crisis. In other words, to contain the serious social damages after the financial crisis and to speed up the return to economic growth, are both goals intrinsically good. Yet, it could be a contributory cause of the following speculation waves that would come up to remove those errors only partially removed and still present in the system.

The formation of speculative bubbles seems to arise from the economic system need to get out from the excesses that pushed the economy down in the instability underworld. In absence of any action to recover the stability, the system seems to run towards a downfall to finally resolve the economy prolonged unstable state. Starting from this extreme determination of the economic system, it should be reasonable to assume that, if there are obstacles on the stability restoration way, could be partially blocked the restyling work assigned to severe depression and to deflation.

\subsection{The Public Debt Heavy Amount after the New Wave of Speculative Excitement}

If this interpretation is well-founded, the system comes out from the financial crisis - partially hampered during the clean-up action - without having removed completely the instability causes. Therefore, the irrevocable tendency to convergence of the economic and natural systems could restart a new cycle of speculative waves to achieve this goal. If this hypothesis is not just a chance, but a real possibility in our future, the condition of many countries and areas worldwide, in this dreadful situation would be quite different from the 2008-2009 financial crisis outbreak. The main diversity factor is lying in the resource availability to face with equal energy the crisis that could develop after a new speculative wave.

The huge flow of public spending thrown into the crisis cauldron has much increased the public debt, which for the G7 countries has reached and exceeded $90 \%$ on average. The public debt rises, with a few virtuous exceptions, widely spread around the world with the same motivation, to mitigate the financial crisis pangs. In conjunction with economic policy measures, the main Central Banks created new liquidity to give to credit some strength and to keep the interest rates very low. In any case, the huge liquidity didn't solve the price trend to deflation, pushed down by the economic uncertainty. Nor tied again the economy loose knots. As mentioned before, the monetary policies play a role as supporting policy lubricant, reducing the side effects arising in the event of a financial crisis, beginning with the liquidity sharp decline and the credit restraint. Neo-Keynesian policies, in turn, are called upon to play an active role in promoting the economy, and indirectly - by resuming the cycle - in attenuating or extinguishing the deflation troubles

The capability to react therefore requires the availability of resources easily usable for spending policies. An option that would be partially excluded, or at least problematic, if the public debt reached and exceeded $90 \%$ in terms of GDP. In this context, now widespread within the industrialized countries, a new use of active Keynesian policies might not have the expected efficacy to mitigate the crisis pangs. In fact, when the limit of Public Debt/GDP ratio is exceeded, a further 
increased indebtedness could result into a reduced effectiveness of the new public resources against the economy crisis.

Whenever the strategy of non-intervention would be chosen, the consequence would be an extension of the economy depression, according to the cliché already experienced by Italy, with a "W" (Double Dip) recession and a substantial decline in living conditions especially for disadvantaged areas. (Cardoso, (1992) With even more dramatic effects if the abstention strategy would be largely widespread. In addition, the public debt heavy amount could increase due to the GDP decline, inside a global context consistently suffering the crisis rigors after the new wave of speculative excitement.

\subsection{The Economy Ten Years after the Great 2008-2009 Financial Crisis}

Face to this scenario of conjectures and assumptions, one fact is appearing as certain regarding the recent experience of the 2008-2009 financial crisis. An economic policy supporting the economy, even with a great increase in public debt, seems to be able to correct the sudden post-crisis recession and to help the economy recovery, nevertheless the economy may remain fragile and restrained. In the context of economies in the post-boom crisis, Keynesian policies to support the economy appear then as a vigorous tool, especially when combined with a very accommodative monetary policy, providing ample liquidity to the system in severe distress.

Most countries after the 2008-2009 financial crisis have made use of public debt to rescue large banks almost near to bankrupt, and to restore the economy vitality blocked by over-indebtedness, which has become incompatible. On the monetary level, the action of Central Banks moved in a deflationary environment to keep interest rates under control, through the acquisition of unprecedented bond amounts, which have inflated the balances of Central Banks.

Figure 3/a and Figure 3/b are showing, respectively, the public debt evolution in the USA, UK, Japan and the World and the monetary mass profile (M3) in USA, UK and China. As can be seen, the public debt growth in GDP \% accelerates during and after the crisis. In the same way, the amount of money M3, which during the speculative bubble formation is rising, follows an accelerated progression during the following years, with the unceasing creation of money to reflate the weak economy.

As mentioned, the irrational speculation wave is a moment of apparent unreasonableness of the natural correction system, which is given when institutions, companies and families appear persistently uncommitted to remove the economy instability causes. When this happens, unfortunately too often, the natural correction system moves symbiotically with the altered economic system, using the singular strategy to accompany the economic system deviations. Therefore, a convulsive scenario is animated in some areas of activity, while the general economy is showing an apparent almost-normality with ultra-low inflation and moderate growth. This actual narcosis is spreading among institutions and families, hiding and distracting the attention from the irrational movement that is troubling the financial system. A strategy indeed - without alternatives - that at the end of speculative pressure will result in a serious financial crisis.

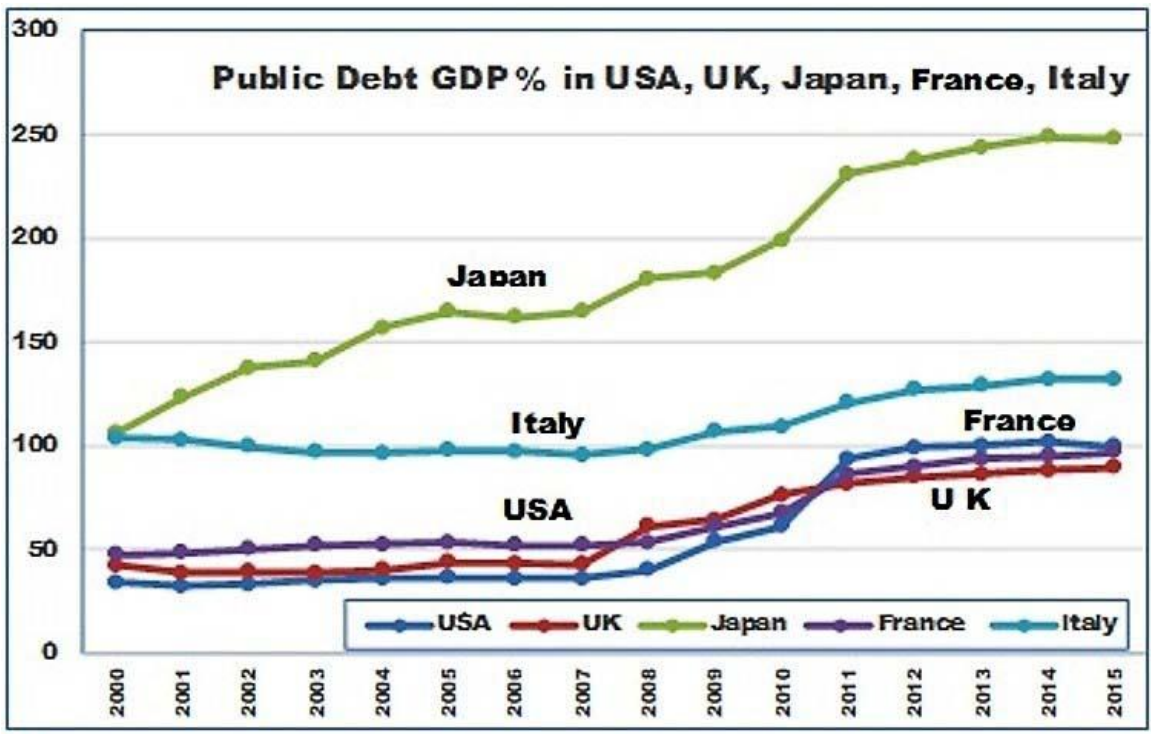

Figure 3/a. Public Debt in GDP \% in USA, UK, Japan, France, Italy 


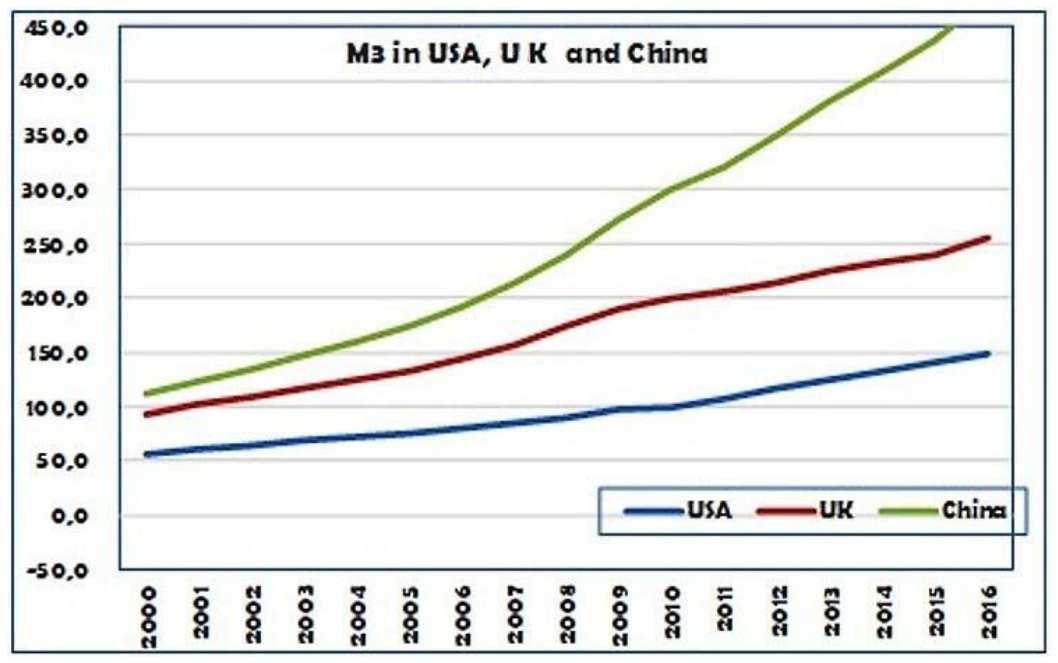

Figure 3/b. M3 in USA, UK and China

\section{Source: Elaboration on OECD.Stat}

The speculation-crisis sequence pursues the inescapable goal of reducing and eradicating those pathologies related to mistakes in the economy management, so to return to the economic and financial health. According to this viewpoint, it's important to evaluate the effects in the medium-term induced by important Keynesian economic support interventions and by the liquidity flow introduced into the system. At this point we can put forward the hypothesis that these countermeasures may somehow interfere and probably limit the extent of natural corrective action.

Once accepted that the corrective action is dragged by the natural obligation to system stability, it cannot be put in doubt that the purpose of the speculation-crisis sequence is representing an intimate and irrepressible need, and certainly not a mere stochastic tendency. Following this line of thought, it would seem acceptable the argument that the correction process does not have margins superfluous or even worse unnecessarily pejorative for the economic climate. On the contrary, this procedure in its integrity should be measured and wisely adapted to solve the problem of system persistent instability.

Therefore, given the suitability of natural correction, it's reasonable to argue that the large liquidity flow in the system in crisis is not a disturbance factor for the normal evolution of the correction course, but rather a sort of lubricant facilitating the natural repair distribution. As to say that the monetary adjustment mechanism of Central Banks could be considered neutral compared to the natural evolution of the post-speculation crisis. Also for this possible neutrality, we can deduce that the sole monetary policy action wouldn't be able to promote an improvement in the crisis situation. An improvement that can be started and then supported by the economic policy impulse. Although support is required also from the monetary policy, playing a mitigating role on the side effects of the financial crisis, such as the cash shortage and the credit asphyxia.

For the liquidity lubricant action on the depressed economy system, we understand why, alternatively, the chronic liquidity shortage accompanying the financial crisis soon is turning into a serious friction factor on the economy destiny. At the time of the 1930s financial crisis, the sudden decision to resume the Gold Standard Interwar, which constrained even more the system liquidity, was the cause of a sharp worsening of the much serious financial crisis. At the time, the monetary rigidity was added to the depressed scenario of the post-speculation economy, worsening it further. Therefore, in these exceptional situations, the non-intervention of the Central Banks, to normalize the liquidity of the system in crisis, becomes a negative third wheel in the crisis evolution.

\section{Results}

\subsection{A Dark Side Could Be Hidden behind the Keynesian Policies}

A limit to the natural correction can therefore be activated by the expansive economic policy, which in turn can be reflected on the economy trend, improving it by the way. So, if we admit that the natural correction is an appropriate measure for the stability return in the altered system, it should be noted that the expansive economic policy can at least partially block or divert the correction process from its natural course. The "destructive creation" action, just to recall J. Schumpeter, of the natural correction would not be completed, because it would be partially "softened" by huge Keynesian manoeuvres (Schumpeter, 1939). We must therefore assume that the economic system correction would remain incomplete. Not only. This "negative yeast", represented by the uncorrected instability, is anything but harmless, 
as it can alter the growth course until to start a new phase of correction of the instability persisting in the system.

In this hypothesis, we can imagine that a new dangerous series of correction courses, with renewed speculative waves followed by financial crises, could appear in the economic landscape. The symptoms of this new economic earthquake may be like those we have already experienced during the previous speculative wave in the Real Estate sector, with low economic growth and weak falling inflation despite the irrational emphasis. Once again, in an apparently positive atmosphere, a new mirage of unlimited development prospects can materialize, while is decreasing the attention to risk in the areas prone to speculation. Once the economy has entered within the attractive circuit of speculation, unfortunately there are no options to the prosecution until the corrective financial crisis.

Therefore, a dark side could be hidden behind the Keynesian policies, besides the legacy of an abnormal public debt requiring a gradual reduction program. However, there is no doubt that this option has made it possible to mitigate the destructive effects of the financial crisis. Implemented promptly and using considerable resources in economies rapidly declining under the blows of the serious financial crisis, these policies achieved some tangible results, mitigating the cycle fall and then giving new breath to the recovery.

Important results indeed, though leaving negative residues for the economy course in the future, due to the public debt abnormal increase. It may be useful at this point to have a look to countries like Italy, only partially involved in the speculative bubble irrational emphasis, though they suffered a "W" severe recession in the 2008-2013 period, followed by a fragile recovery. The reason for the harsh treatment suffered by Italy is to be charged to the large debt that has weakened the economy financing. This fragility has refrained, due to reflections on the debt under pressure, from interfering with the recession run by broad Keynesian policies to support the economy. In fact, Italy had a public debt of $120 \%$ of GDP accumulated by the eve of the 2008-2009 financial crisis, and this increased with the GDP decrease. Essentially, the "Beautiful Country" has not been able to alleviate the weight of the crisis by enabling an adequate amount of public expenditure to counteract the negative economic situation.

After almost a decade after the 2008-2009 financial crisis, we can then note that the strategies to cope with the severe recession and deflation have not been unique in the context of industrialized countries. Those countries that in the past were less prodigal in applying the public indebtedness, have invested instead extensive resources for intervention policies to support the economic situation. Others, and particularly Italy, which had accumulated a heavy public debt, couldn't or didn't want to follow this crisis intervention strategy, and have undergone a deeper deflation and a cyclical inversion.

Countries that couldn't or didn't want to invest public resources in the economy into recession remained exposed to the bad wind of forced correction. The natural correction is not a uniform process, but ideally is calibrated to react according to the instability degree of the different economies. Following the approach that the speculative wave is born to put the unstable economic system back on the compatible growth path, we should see the return to a balanced development in those countries that have suffered the corrective creative recession. A positive effect that could not occur, instead, for the economies of those countries that have counteracted the natural correction through strong Keynesian measures, since the instability has not been even partially corrected.

In absence of new mistakes in managing the economy, the natural correction should be able to clean up the system from the damages accumulated for past mistakes. When the correction has been done then, the economic system must return stable while a new development phase would start. The bill to be paid is bitter, but the correction strength depends on the mistakes accumulated in the economy management. In the end, in a medium-long-term context, it should be worth it. The natural and optimal condition harmonizes the economy growth according to a course, never cyclic, in line with the natural system evolution.

The current scenario of the main economies only partially responds to the forecast of a different statu quo over ten years after the speculative bubble burst. In fact, a growth slowdown accompanies a low inflation in many countries that have counteracted the phase of natural correction. A condition that is not different in the group of countries that suffered more the correction effects. In fact, the expectation of an improving economy performance has not been realized even in those countries that have suffered more the weight of the 2008-2013 correction.

In the case of Italy, particularly, a low control on the current spending growth factors and the GDP reduction have contributed to the public debt increasing, which in 2016 reached 135\% of GDP. Unfortunately, the recession mechanism driven by natural correction does not appear to be able to eliminate the instability cause in the case of excessive indebtedness. Debt that - in the total inertia of the institutions - undergoes an increasing pressure due to the economic growth weakening. An excessive public debt in any case represents an unstable economy; so, a doubt about an incomplete correction still is present for heavily indebted countries, which avoided anyway whatever important intervention. 


\subsection{The Hypothesis that the Choice of Keynesian Solutions during and after the Post-Speculation Crisis Would Be} Reasonable

The overview of the main countries - ten years after the speculative bubble burst - seems to be relatively homogeneous, sanctioned by the creeping deflation trend, with weak or medium-low performances. A context leaving some open doubts about the near future evolution. In fact, the 2018 growth forecasts for major economies - according to the International Monetary Fund - fall below 2\% with an inflation slowing down around 1\% or little more. This pattern of apparent regularity and similarity can be seen from different points of view.

In the first place, the relatively weak results in terms of growth can be read as a result of the exponential growth in public indebtedness during the crisis years. In other words, the legacy of the 2008-2009 severe financial crisis is the excessive indebtedness, which in turn is the cause affecting the world economy and its balanced development. Ten years after the bursting of the speculative bubble on sub-prime mortgages, the world's major Central Banks still consider necessary to give the world economy a helping crutch, by ultra-accommodative monetary policies (interest rates near to zero and Quantitative Easing - QE).

The world economy overview thus seems fairly homogeneous. However, the research of the affecting factors could be not exhaustive, and not focused only on the public sector high indebtedness. The problem of the different treatment reserved by the various countries to contrast the natural correction is still outstanding as also, above all, the possible effects that this differentiation may have on the economic landscape evolution, which anyway is showing now a relative similarity.

In general, it should be admitted that the natural correction function has the irrevocable purpose of leading the economic system to the path of economic compatibility with the environment state. It follows that when correction has been developed and completed, it should lead to a compatible and stable economy recovery. We noted already that this phenomenon didn't happen for the countries that suffered more the recession wave, probably because of the existing heavy debt. However, in countries such as Italy, with poor resources to face the severe economic crisis, it is probable to witness a future recovery strengthening with a deflation exit, if and when a credible debt reduction course would start.

A second group of countries, however, has put in place the adequate Keynesian strategies to counterbalance the decline caused by recession and to push ahead the recovery. For this group of countries, it can be expected that the economic system has remained unstable for having obstructed the natural correction full manifestation. The natural correction forces, not exhausted and latent within the economic system folds, could swell again a speculative wave, starting from technology sectors and Stock Exchanges. In this hypothesis, wherever acceptable, we should re-experience the events of the years preceding the 2008-2009 great crisis. The symptoms again would be the usual ones: an increasing economic climate, a weak and creeping deflation tendency, a relative quiet feeling at the initial stage of the phenomenon.

Theoretically, the assumption that a substantial part of world economies may undergo a new speculative surge is quite plausible. To some extent, it must be admitted that the accumulation of human errors in the economy management is closed and resolved only if and when the corrective storm would rebalance the situation. The amnesty hypothesis, after these attempts to force the development line, wouldn't be admissible for the simple reason that otherwise some systemic errors - with unexpected evolutions - would be maintained inside the system.

However, it could be evaluated whether the use of strong Keynesian therapies to counterbalance the post speculation depression strength would be a reasonable choice. In the sense that, in terms of sacrifice done for the system return to the stable condition, the correction sequence by partial steps should be less heavy than the non-intervention option. In fact, in the case of non-intervention to shield against the crisis, many factors worsening the declining economy can be cumulated. Factors that could be prevented just by mitigating the recession imposed by the natural correction. In the case of Italy, the presence of heavy public debt played a role by accentuating the economic decline. Not only. The debt greater burden, due to GDP fall, has blocked in turn the recovery phase. So, becoming, at the end, an exasperation factor of the recession.

The hypothesis that the choice of Keynesian solutions during and after the post-speculation crisis would be reasonable is not to be dismissed. Especially if we reflect on the public debt widespread among the major countries, precisely because of the massive use of support measures to mitigate the recent financial crisis pangs. In the hypothesis, unfortunately quite probable, that a new speculative crisis is preparing, can we reasonably consider the choice to face the new calamity with massive public resources? It would therefore be reasonable to use again Keynesian interventions, despite the huge burden of public debt, which is really a third uncomfortable wheel within the world economy.

Since we are facing a new frontier, we can think about this eventuality by looking at the countries affected by the crisis, who have not used strong support measures because there weren't available resources, due to an excessive debt. What would have been the expected results if they'd taken the increasing debt way to protect the economy? It may be argued, on a mainly theoretical plan, that the economy support through new debt could have prevented the deep "W" 
recession during the years 2008-2013, so containing the recessive effect at around $2 \%$ and giving some breath to recovery already in 2010-2011.

If this hypothesis were correct, the debt increase due to GDP fall would have been lower than the case of a long recession and slow recovery. In conclusion, it could be argued that in both cases, with or without intervention, there would be a public debt increase almost similar. Notwithstanding, the economic affair in the case of intervention would be less troubled with a less unstable return to the pre-crisis conditions.

This hypothesis is based on the assertion that the large public resources maneuver, in the case of a severe post-boom financial crisis, may have the same calming effect on the recession both in virtuous countries and in countries with a GDP debt over $100 \%$. Nevertheless, this assumption may be partially invalid. In general, it must be admitted that injections of new public deficit expenses are less effective, because of excessive debt. But this lower efficacy may be eased in the event of a deep recession with a concomitant deflation. Not only because of the substitution effect produced by the new spending about the expenses removed by recession, but also for the mitigation of the side effects produced by the economic situation sharp decline and by the uncertain prospects.

\subsection{Ten Years after the Last Decade Great Financial Crisis, Speculative Bubbles Are Forming?}

In Figure 3 we can look at the inflation and GDP trends in the USA, UK, Spain and China. The variables are vertically stacked in the graphs (Pile Charts), so the quarterly GDP area is delimited below by the inflation line. The stacks of Inflation and GDP trends over the period 2004-2017 offer the opportunity to observe the coincidence of the two variables, following a mini-cycle within the year, then confirmed in the surveyed countries. Interesting to note that the cyclic rhythm, particularly obsessive in the Spain box, is repeated also for China, where the progressive deflation trend in prices is not reflected on the GDP progress.

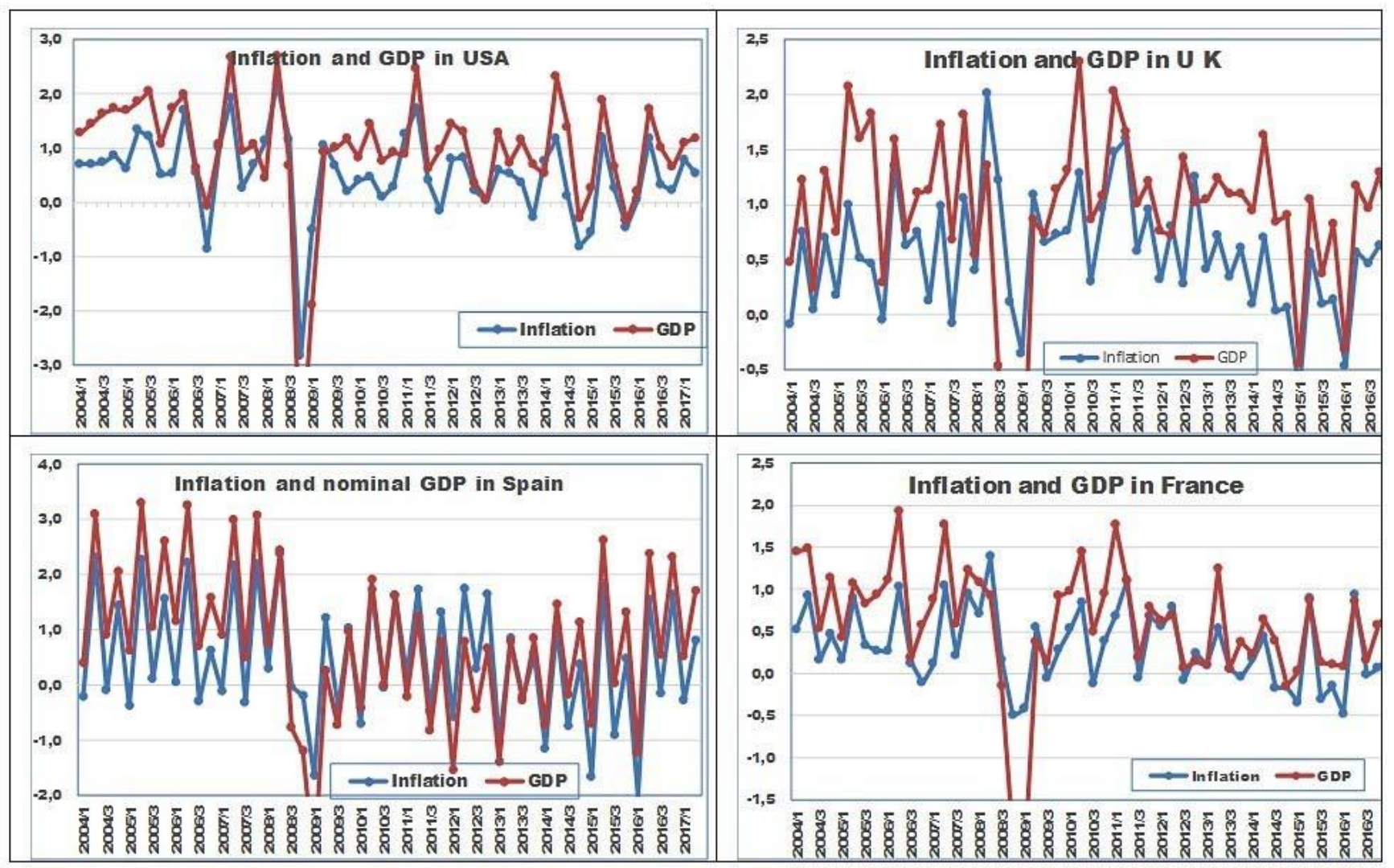

Figure 3. Inflation and GDP in Pile Charts for USA, UK, Spain and France (2000-2017)

Source: Elaboration on OECD.Stat

To evaluate these trends, it should be noted that: -The mini annual cycle, as the cycle of Schumpeter's economic model, are both behavior patterns of an unstable economy; -Similarly, the combined coupling between the economy cycle and the inflation cycle is an important element within the instability universe; -In particular, the yearly mini-cycle accentuates the oscillation between minimum and maximum level during the speculative phase, and even more in the turning point leading to financial crisis.( Bernanke, 2000)

Moreover, regarding the inflation mini-cycle, the observation highlights that prices are near to zero about one year 
before the bubble breaking, while prices will expand their movement in the following period until the crisis outbreak. The price declining trend during the 2000-2007 bubble development, is partly concealed by the effect on prices caused by the oil increase, driven upward by the speculative emphasis. In fact, for the entire period of the speculative bubble formation, in the major industrialized countries the inflation remains around 2-3\% and then falls and almost disappears about one year before the financial crisis, nevertheless increasing again due to the speculative game final sprint.

It should be emphasized that the rhythmic in the inflation cycle becomes important when assessing the possible presence of a speculative risk in formation. The amplitude between the maximum and the minimum in the inflation mini-cycle, in fact, tends to increase in the speculative boom acceleration phases, almost a sort of ongoing process accelerated breath. The price system tendency to a deflationary behavior is a simple and authentic measure on the economic instability issue with the potential formation of a speculative bubble. The price system deflating trend, in fact, seems immune from the speculation rising exasperation and thus is showing the real weak aspect of the unstable economy.

The economy cycle in the bubble formation stage, in turn, is moving quite cautiously, so contradicting the appearances of a development driven by the speculative motion. Even the quietly moving economy performance is indicating the presence of a serious anomaly. As clearly shown in all Figure 3, the economy cycle trend during the formation phase tends to be contained, differently from the inflation cycle which is proposing instead a rhythmic feature with a mini-cycle annual cadence. Please note that graphs are showing the variables in stack (Pile Charts), therefore the similarity between the two cycles is only apparent. Indeed, the economy cycle seems to be almost neutral regarding the effort imposed by speculation and moves in a fairly cautious and relatively constant way.

It's evident that the energy shown by the economy during the speculative phase is the unplanned byproduct of the boom. Indeed, the unintentional product of this growth due to speculation will be fully eliminated during the financial crisis ending the excitement. On the other hand, during the speculative phase, the excitement is transformed into a growth that, though moderate, is able to generate a "mirage effect" on future prospects, and this effect will also drag employment with the false expectations thus created. The speculative system collapse involving the real economy will be therefore even more devastating for the employment sector.

Of course, regarding the two variables in this game, the inflation cycle and the economy cycle, the first one offers an important warning signal on the speculative storm crossing the economy. The economy cycle, on the other hand, in concert with the nominal price arrhythmia, is showing a growth relative tranquillity opposed to the vortex created by speculation. These characteristics are resulting quite evident from an analysis of the motion of the two cycles in those countries that have fully experienced the speculation in subprime mortgages during the second half of the 2000s.

The strong excitement of the inflation mini-cycle is particularly evident in the UK and Spain, while it's accentuated also in the USA from 2004 to 2007. In the same countries, the GDP line follows a slight upward trend then tending to decline with the development of the speculative movement until the final crisis. As we can understand analysing the lines of the two variables in the stacked graphs, there is a clear link between the two variables (Cossiga, 2017)

Therefore, we could identify the pre-speculative phenomena of speculative troubles by looking at the excitement of the inflation mini-cycle and, at the same time, at the economy cycle trend almost calm, accompanied by a relative employment growth.

Unfortunately, once into the irrational growth escalation, an escape way is not in sight. The natural mechanism seems irreversible. On the other hand, this seems comprehensible. In fact, the no-risk growth mirage is an effective drug for institutions, companies and families, mislead by the false myth created by the speculative wave. A mirage that goes on, almost until the final crisis.

\subsection{The Financial Fragility Is Causing Phenomena Somehow Similar the Speculative Phase}

As already mentioned, the speculative bubble panorama is full of shadows and lights in those countries that haven't followed the pattern of a massive public deficit intervention to mitigate the crisis pangs. In Figure 4, are shown the Inflation and GDP trends in Italy and Belgium, two countries that, at the 2008/2009 crisis outbreak, cumulated over 100\% of public debt. A debt condition excessive, so making improvident to take the public rescue road against the serious crisis. Below, in the same graphs, are then summarized the Inflation and GDP profiles in Norway and Australia. These two countries at the global crisis outbreak had a reduced public debt (Norway at $14 \%$ and Australia at 5\% of GDP).

All four countries didn't use massive Keynesian manoeuvres to face the crisis, either by necessity or by choice. The differences in after-crisis time are obvious. Both Italy and Belgium have endured a deep crisis in 2008-2009 (about 5\%), then followed by a new smaller recession in 2013 (about - 0.5\%). Instead, the other countries considered in our analysis, at that time with a very low public debt, had a mitigated inversion of the economic cycle, particularly Australia. 


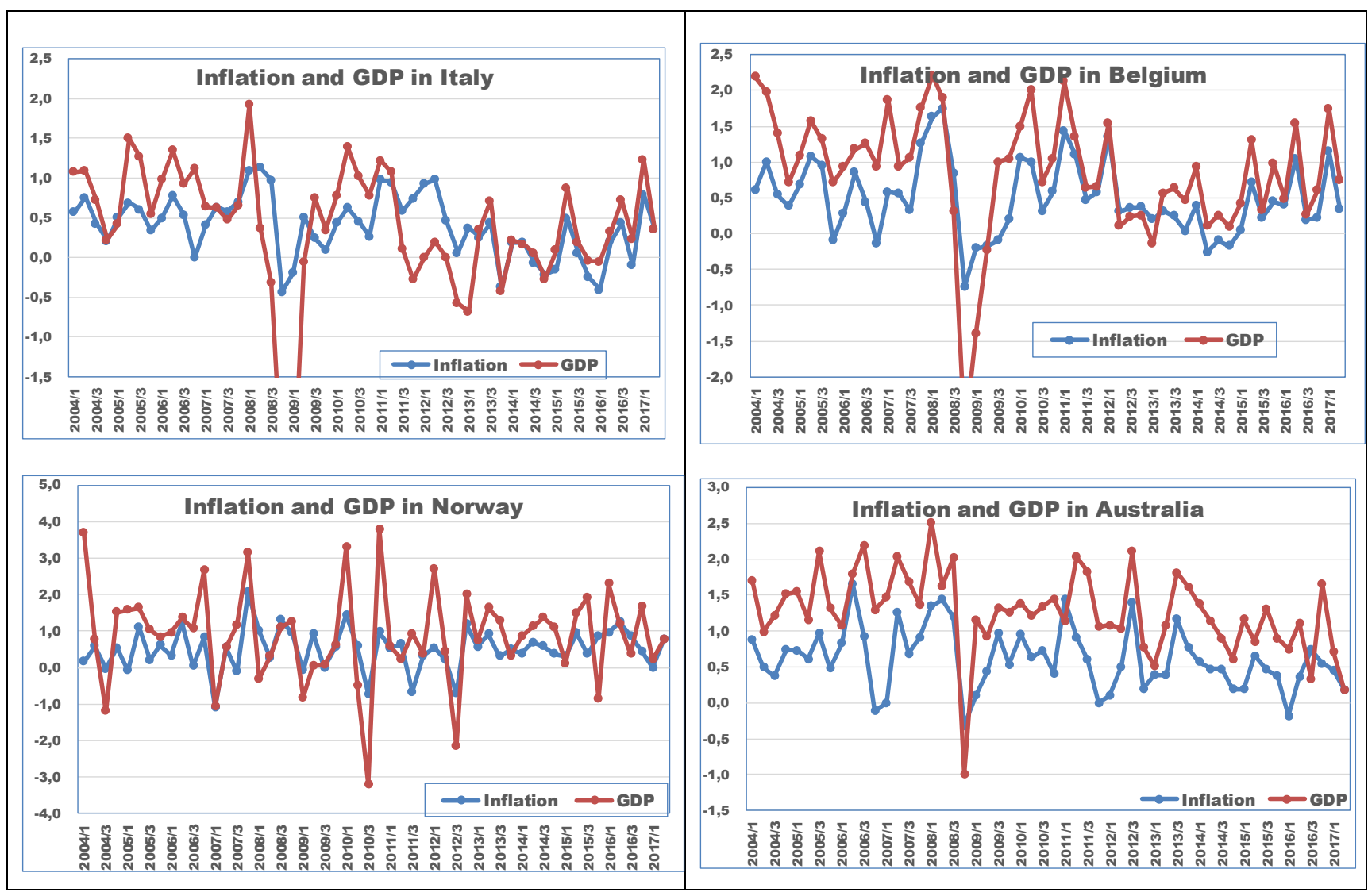

Figure 4. Inflation and GDP in Pile Charts for Italy, Belgium, Norway and Australia (2004 - 2017)

Source: Elaboration on OECD.Stat

In fact, fragile countries that had cumulated a public debt beyond the limit of 90-100\% in relation to GDP, suffered a strong blowback for the world crisis. The recessionary crisis was in Italy deeper than in countries such as the USA and UK, though these countries have anyway experienced and even spread the speculation irrational emphasis. The reasons are most probably related to the financial fragility and, perhaps, to the consequent lack or low defense with Keynesian tools. The financial fragility for over-indebtedness (>90-100\% in relation to GDP) is causing phenomena not comparable to those occurring during the speculative phase, but somehow similar, as low growth and deflation tendency of the price system. This is a pre-crisis scenario that has facilitated in these fragile countries a strong repercussion of the 2008-2009 financial crisis. Again, on the issue of countries with heavy public debt, we should note the sharp slowdown of the economic cycle already in the first quarters of 2007, therefore with about one year ahead of the general crisis outbreak.

In the case of a public debt beyond the limits as explained before, there are no phenomena comparable to the irrational speculative excitement. On the contrary, the subsequent financial and economic fragility will be long-lasting and will affect the course of economy (weak) and inflation (tending to deflate). On the other hand, the resilience of the country chronic weakness exposes these economies to the amplification of external shocks, as in the case of the post-speculative wave widespread outside by the world's major economies.

As mentioned, in the series inside Figure 4 are included inflation and GDP trend lines in Norway and Australia, two quite virtuous countries in terms of public debt (11\% of Australia GDP in 2011). Analysing the trends, there is a considerable dissociation between the profiles of the two variables (most notably in Australia), testifying as the two countries were relatively out from the speculative process. In Norway, the speculative excitement with the consequent relative correlation between the two variables is occurring only in the year preceding the large speculative bubble worldwide outbreak.

The intimate bond between the two variables, Inflation and GDP, is the symptom of a strong excitement of the economy and of an instability trouble due to human error in the economic system management. Therefore, dissociation and neutrality in the trend of the two variables is providing the image of a desirable and relatively stable economy condition. In the graph section regarding Australia, after a modest excitement due to the global crisis, we can see the economy trend of that southern country moving with an obvious dissymmetry against the price movements, while the inflation fluctuation also decreases and flattens along the last few years. Similar considerations are concerning also the Norway, where there is a progressive flattening of the inflation line, while for both countries the efficiency of the economic 
system is quite improving.

In the Italy section, the Figure 4 shows that the relationship between the two variables is weakening after the decline for the severe financial crisis, perhaps signaling a preliminary dissociation of the relationship between the two variables. This is an index that the severe recession has partially improved the country instability state. The singular revival of the inflation mini rhythmic oscillation is perhaps related to the government's choice to keep the public spending high, with a further increase in public debt. More delicate is the assumption that the rhythm restart of the (low) inflation mini-cycle may be predictive of a new speculation wave, somehow amplified by the country because of its unresolved financial fragility.

By the way, the same plot can be read in the Belgium recent (low) inflation profile. Also, this central European country is suffering for high debt and slow rise, as in the Italian case. As in the case of the "Beautiful Country", after a quiet phase of the two variables under review, linked to the economy stagnation due to the financial crisis, the tension somehow revived the inflation mini-cycle. It's not unreasonable to suppose that the mini-cycle agitation restart is a premonition for a speculative wave restart in Western area and China. A similar phenomenon is not felt in countries with low public debt and more stable economy, such as Australia.

\subsection{Some Countries that Have Invested a Lot of Resources to Counteract the Financial Crisis Imbalance}

Let's now expand our analysis to those countries that have invested a lot of resources, thus causing a debt burden, to counteract the financial crisis imbalance. To look at these realities, in the pile charts of Figure 4 are shown the movements of the two variables, Inflation and GDP, for USA, UK, France and Spain. For the USA, in the years following the 2008-2009 crisis, a sustained inflation course (quarterly figures) can be observed, which since 2014 follows a gradual reduction (in the 2nd quarter of 2017 at 1.3\%). The GDP profile seems to be delayed by one quarter compared to the inflation variable, and like this one is showing a gradual decline. Ambiguous signals, indeed. On the one hand, they are typical of a scenario with high public indebtedness and of system instability. On the other hand, the progressive decline of the two variables may indicate the middle phase of a new speculative phase movement, during which the inflation is near to zero and also the economy is lagging before the final unrestrained rush (Geithner, T. F. (2015).

We can find the same (low) inflation line trend in France. Also in this case, the rhythm seems to accelerate from 2016, although the oscillation amplitude is reduced. The GDP trend is still weak, although delayed by one quarter. All the considerations on the large public debt burden, also apply to France. Heavy indebtedness that may be the cause for the modest results on the ground of economic growth. The fluctuation increases in the two variables (Inflation and GDP), follow however the same way mentioned for the USA, then suggesting that it could be repeated the sequence already seen since mid-2000s, when with similar configurations the speculative acceleration started.
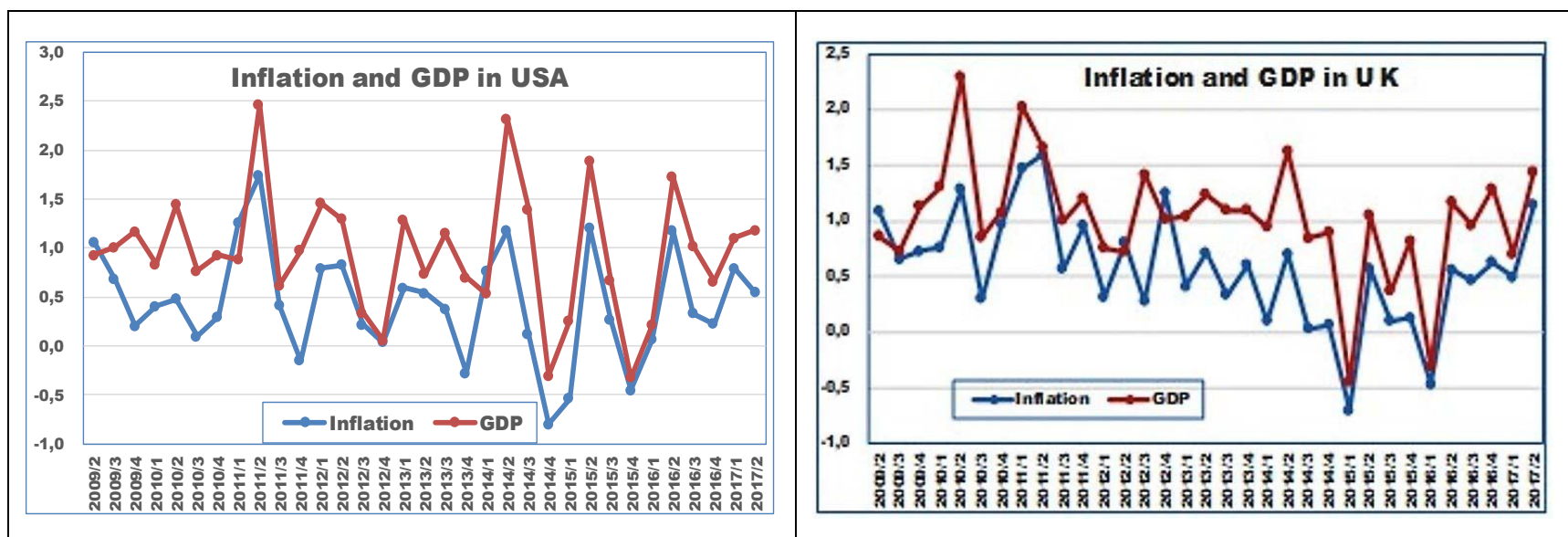


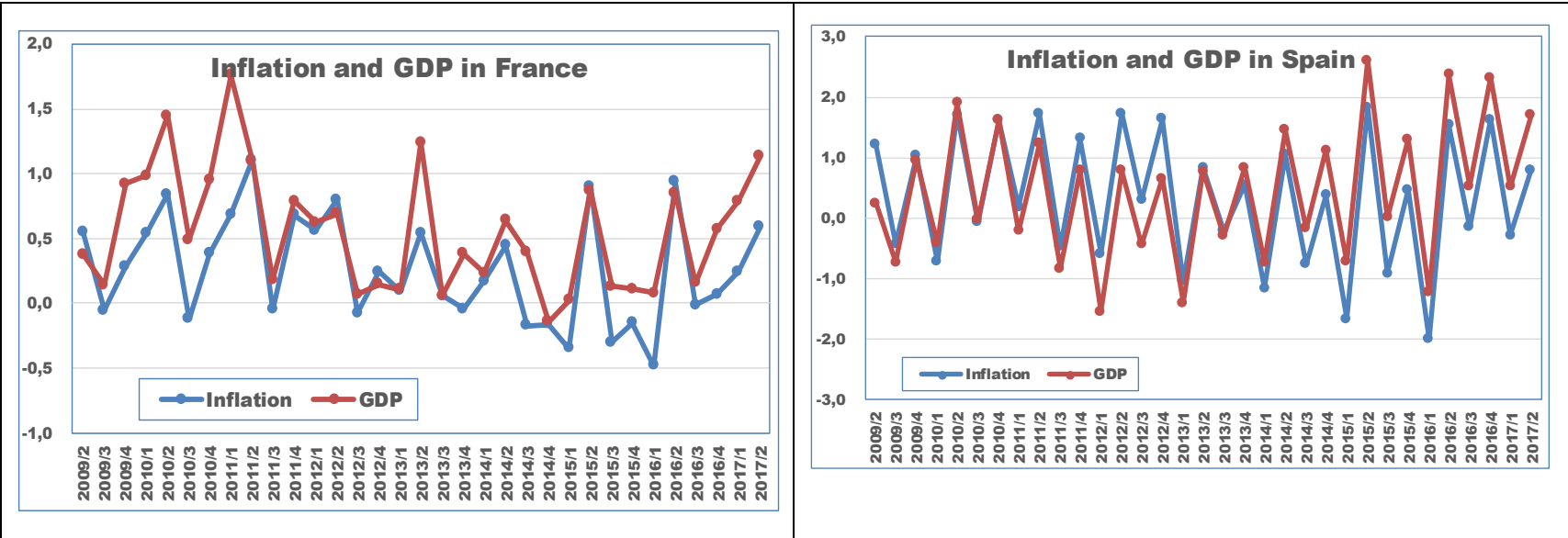

Figure 5. Inflation and GDP in Pile Charts for USA, UK, Spain and France (2009-2017)

Source: Elaboration on OECD.Stat

The configuration of the two variables in Spain during the last decade is quite alarming. As can be seen, the rapid pace of the two variables doesn't change so much from the 2000-2008 period. In this case any interference of public debt, also in this case too high, on the course of the two variables should be excluded. It's sufficient, in fact, to consider that during the speculative phase, the Spanish debt was low, equal to $30 \%$ in 2007, yet the speculation peak was very strong. Situation quite similar today in the behavior of the two variables, with a public debt close to $100 \%$ of GDP. Perhaps it's more realistic that the economic condition emphasis, though limited, may be due to the economic system incomplete correction in Spain, despite the "W" recession corrected firstly in 2009 and then in 2012 and 2013. It's reasonable to suppose that the speculative reaction intensity in the second half of the 2000s was stronger than for other European countries. Therefore, the instability residues still unresolved may push once again to a new potential speculative increase.

Great Britain follows approximately the developments occurred in other European countries. Recently, after the English vote on EU membership (the so-called Brexit), the decline in UK currency against major currencies is now affecting the British cost of living, due to the increase in the cost of imports. Consequently, comparison doesn't appear to be useful.

\section{Discussion}

The above concise analysis doesn't offer consistent results to argue that in the major world economies it's again growing a new wave of irrational speculations. However, there is no doubt that the analysed scenario shows a widespread economy instability at the continental level, as evidenced by the inflation weakness and by the economic system declining efficiency. The picture is, so to speak, clouded by the residue left behind by the 2008-2009 financial crisis, with a widespread high indebtedness, particularly public, which is difficult to control due to the low growth and to the deflation tendency.

In any case, it's useful to look at the images drawn by Figure 5. The main analysed variables (Inflation and GDP) seem to show a profile that in recent years doesn't differ too much from the profile recorded between 2004 and 2007, namely during the speculative crisis development along the previous decade. Moreover, when the previous bubble was forming, the Stock Market had a somehow pioneering role with the speculation on the so-called Dot-com, followed by soaring oil prices not justified by the real economy condition. The recent Stock Market hike of high-tech companies, such as Google, Apple, Facebook, Amazon ${ }^{1}$ and others, is like the uncontrolled courses of the companies involved in the New Economy $^{2}$ speculative bubble at the last decade beginning. The similarity of their behavior, to those during the years before the 2008-2009 financial crisis, is leading however to not underestimate the possibility of the speculative mechanism revival.

\footnotetext{
${ }^{1}$ Amazon, Apple, Google and Facebook. These West Coast companies today have the same Stock Market value of Spain GDP, that is the twelfth world power. Their explosion has disrupted entire sectors of the economy, from commerce to publishing, from advertising to music.

${ }^{2}$ The term Dot-com is also used to identify those companies that, born after the substantial capital surplus generated by venture capital, and after the great Equity Stock Market optimism during the late 20th century, set up their business primarily focused on Web service delivering. In many cases, these companies had to deal with the lack of innovative ideas, experience and management skills. The Dot-com were the negative champions of the New Economy's speculative bubble in the early 2000s, when many of them failed and generate the New Economy real recession.
} 
For the search of a new speculative crisis warning signs, it could be also useful to look at Figure 6, which represents the 2000-2017 inflation lines in the USA, Europe and China. It is quite interesting to note that in 2015 the inflation curve in all major continental areas in question goes down near to zero, and then rises while remaining weak. The inflation declining trend, anyway remaining below 2\% (the reference parameter observed by Central Banks), is considered a sort of rebus for the misalignment of GDP trend, which is moderately growing without apparently affecting the inflation profile.

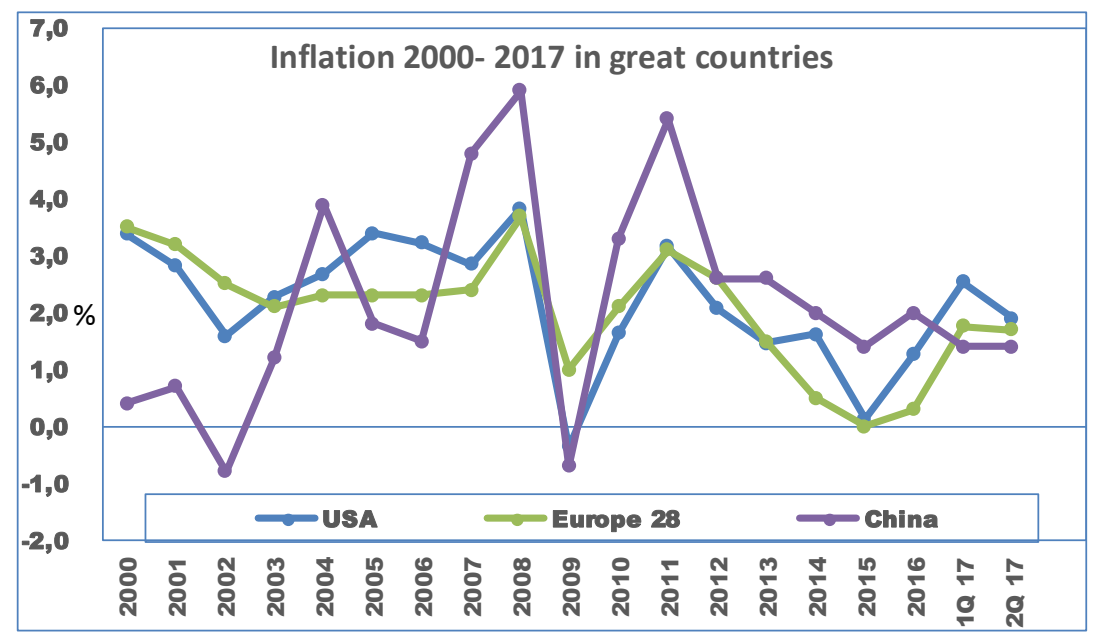

Figure 6. Inflation in main continental area

Source: Elaboration on OECD.Stat

We should carefully analyse the apparent divergence of the two variables, because this misalignment is a premonition of the possible tendency of systems to have a speculative excitement. In a scenario where is maturing a speculative crisis we can observe a slow but steady decline in the inflation rate, decline that continues until to tend to zero. When the speculative phase becomes severe then, inflation is increasing again, though remaining low. The GDP - in misalignment with the Inflation variable - remains at a level moderate or low, if related to the tension caused on economy by the speculative stress.

In a speculative scenario, therefore, the most obvious contradiction is given by a declining inflation, notwithstanding a small final increase and the economy growth though at a moderate level. Both signals are divergent with the system excitation state and, therefore, significant to make an assessment of events in preparation within the economy.

We can say that, during the state of irrational excitement, the inflation rate seems to play synchronously with the economy instability, thus showing a system tendency towards deflation. The tendency towards deflation is a characteristic signal of an economic system with over-indebtedness. The economic system growth is dragged - but just partially - by the euphoria exciting some sectors and therefore is registering a moderate but steady GDP rising. Both variables are therefore ambiguous parameters contradicting the apparently strong economic situation. Ambiguous indeed, because at a first sight they could be mistaken for the mirage of a balanced system showing compatible growth and inflation under control.

\subsection{Possible Similarities of the Variables Profile Recent Behaviour Compared to the Last Decade}

This ambiguity can be exposed. In fact, in a stable system the two monitored variables (Inflation and GDP) move independently. Inflation seems neutral related to GDP trend. Economic growth, in turn, has a linear trend, not marked then by the conjuncture cyclical pace so remaining compatible with the environment in which it is operating.

In an unstable system, the scenario ambiguity can arise from the economy behaviour, which is growing with a constant pace. The wake-up call then is played by the inflation behaviour, and it's to be found in the behaviour of prices obstinately tending to low. As above mentioned, the fluctuations of the Inflation variable in the annual mini-cycle are wider, in relation to the system instability degree. Therefore, they become bigger in the imminent end of the boom and also during the financial crisis.

Figure 7 are reporting, for the period 2000-2017, the quarterly inflation in the USA, Italy, Spain and Sweden; below, is reported also the quarterly inflation in France, the Netherlands, Canada and Australia. As you can see, the oscillation rhythm is different among the monitored countries, but a certain synchronism of cyclical rhythm in the various countries is confirmed. For all the countries concerned, the inflation mini-cycle oscillations are accentuated in the final phase of the boom. Then they continue with a tendency to deflation in the years of the financial crisis, which for some countries 
continued with a "W" recession. Since 2016, the price deflation profile is moderated, but the mini-cycle pace doesn't change.

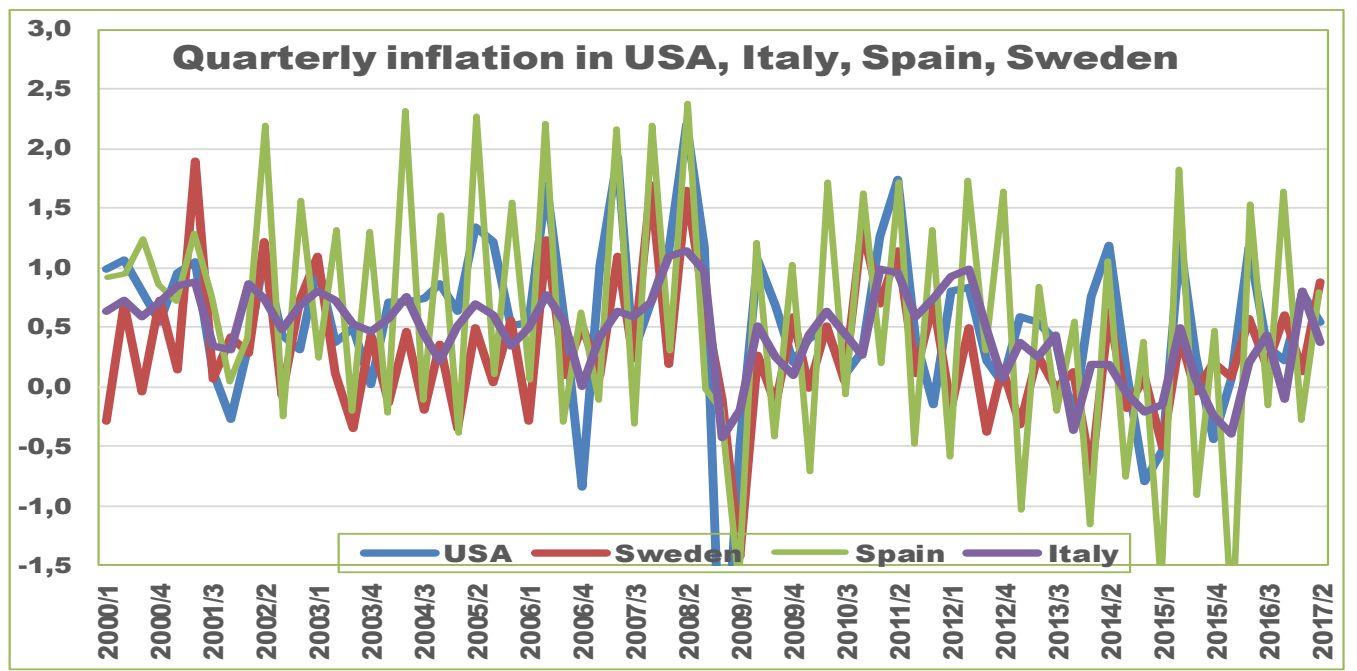

Figure 7/1. Quarterly Inflation in USA, Italy, Spain, Sweden

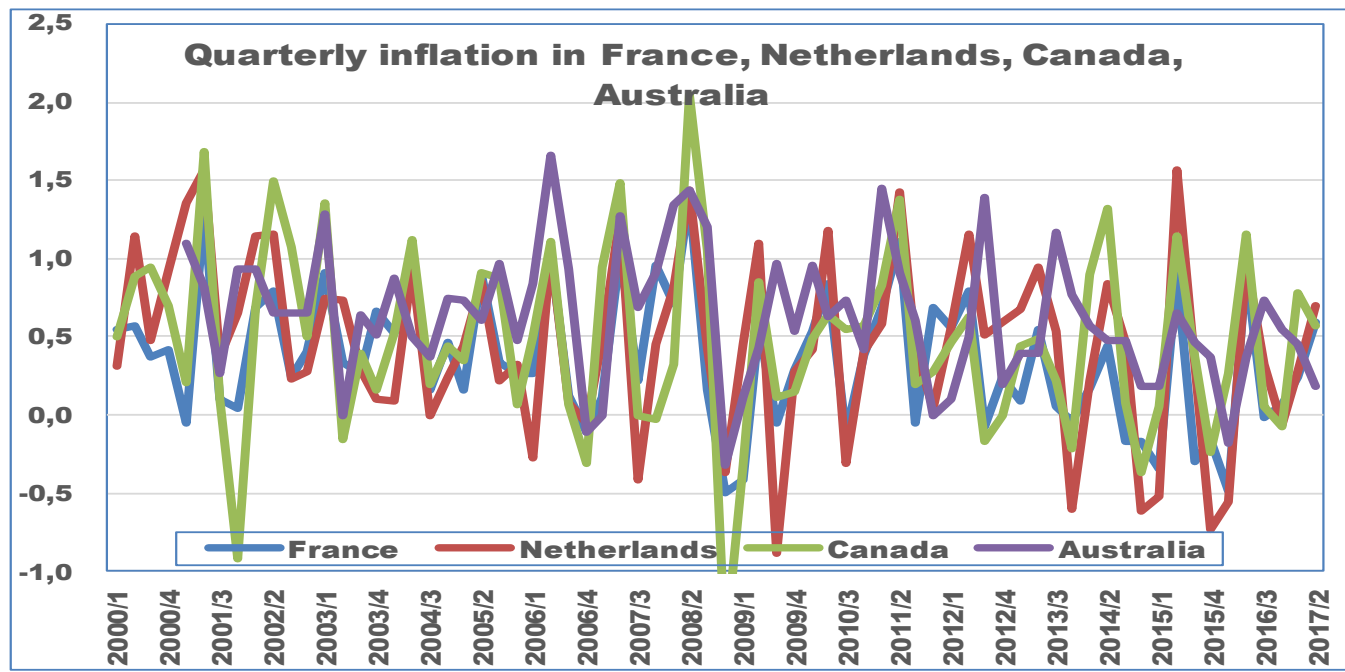

Figure 7/2. Quarterly Inflation in France, Netherlands, Canada, Australia

Source: Elaboration on OECD.Stat

The amplitude of the inflation mini-cycle oscillations seems to be important, because is advising an unstable state in economy together with the tendency to start and fuel an irrational excitement. In the early 2000s, the preparation for the speculative excitement is represented by the usual mini-cycle, which in the years from 2003 to 2005 is showing a progressive trend of economic systems to the deflation. At the same time, while the oscillations do not change their rhythm, nevertheless the height of cyclic waves is reduced. In the following two years, the first step before the 2008-2009 financial crisis, the level and magnitude of inflation fluctuations are rising both.

Looking for possible similarities of the inflation profile recent behaviour compared to the last decade, we can note that:

- After the long and deep recession started in 2008, the still strong inflation wave continues to show a cyclical profile (mini-cycle), instead of moving towards a smoother profile without continuous cyclical breaks;

- In the two-year period 2014-2015, a rise in price deflation was noted in many of the analyzed countries, and at the same time the mini-cycle wave was excited. This trend seems to repeat the one in the early 2000s;

- The wave amplitude of the inflation mini-cycle is showing again a decrease, somehow following the one designed when the 2004-2005 irrational excitement was developing;

- There is a gradual synchronicity of the inflation mini-cycle in the observed countries; it is a significant signal - if confirmed - about the starting of the speculative boom mature phase. 
The employment may be a further element of uncertainty about the real state of the economy. During the speculative excitation phase, in fact, employment can follow a growth course. The mirage of a long-term positive outlook blurs the risk assessment during the excitement phase and can induce businessmen and companies to make investments, even with new employment. It is therefore unlikely that even during the preparation phase of speculative excitation, there could be an unemployment decrease. In the current context, the downward unemployment wave from 2013-2014 is a good signal. However, it can be a cryptic sign about the economy destiny in our future, at least until the concerns about these abnormalities would be overcome.

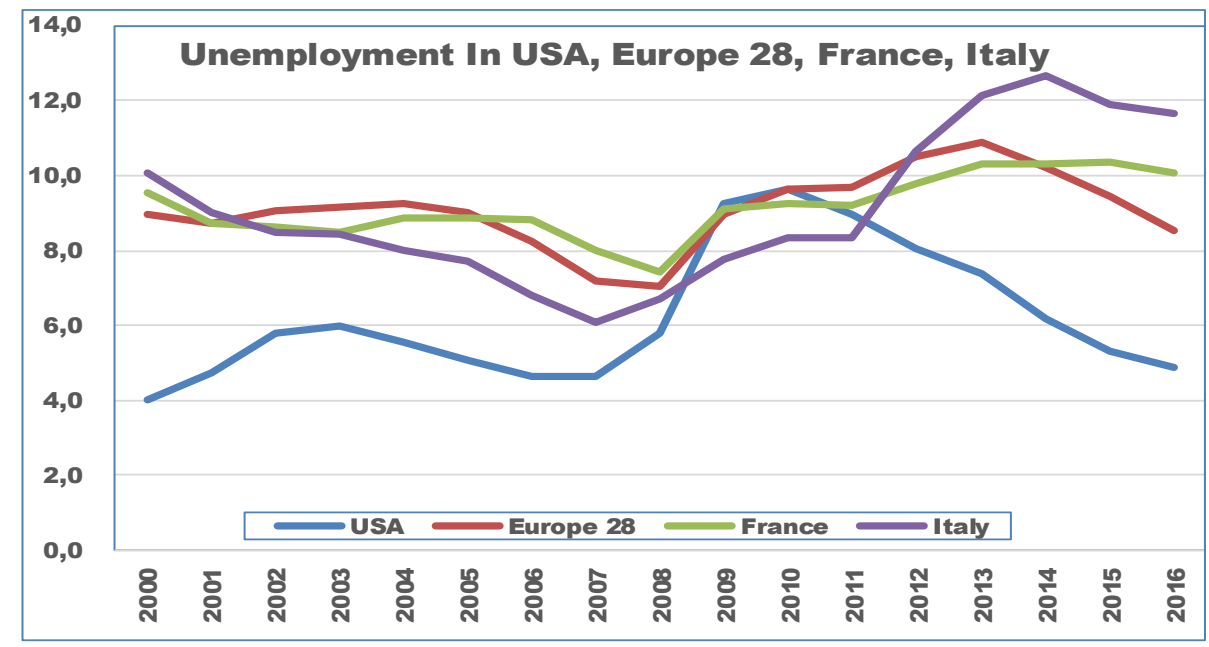

Figure 7/3. Unemployment in USA, Europe 28, France, Italy

Source: Elaboration on OECD.Stat

\section{Conclusion}

These important but not definitive signals could be confirmed if in the future we would experience an inflation recovery at the level of major continental areas. Far from being a good indicator of a steady economy recovery, as many economists say, an even contained resumption of inflation may be the sign of a new speculative pressure.

All that said, the situation seems uncertain at present. This uncertainty evaluation is partly due to the spread among the major economies of a significant public debt, over $90 \%$ in terms of GDP. Over-indebtedness is a cause - in the real economy - of a scenario similar to the initial phase of speculative excitation: low economic growth, deflationary tendency, but unemployment tending to increase. The indebtedness excess doesn't cause usually the activation of a speculative excitement,

In some way, at least during the speculative process initial stages, the two scenarios may converge and even resemble. Therefore, the current framework does not provide the necessary tools to decide whether the current instability level is likely to deteriorate in a renewed irrational excitement of the system. Against expectations, the signal that the system could run into the financial crisis will be given by a rising inflation, followed by a slight increase in economy and employment in the major continental areas.

\section{References}

Bernanke, \& Ben, S. (2000). Essays on the Great Depression. Princeton University Press - Princeton, New Jersey.

Cardoso, E. (1992). Inflation and Poverty. in NBER Working Paper \# 4006. https://doi.org/10.3386/w4006

Cargill, T. F., Hutchison, M., \& Takatoshy, I. (1997). The political economy in Japanese monetary policy - Massachusetts Institute of Technology.

Cossiga, G. A. (2016). L'inflazione, la Deflazione, il Ciclo Economico e l'Efficienza dei Sistemi. - International Multilingual Journal of Science and Technology, 1.

Cossiga, G. A. (2017). Stability and Instability of an Economic System: Considerations. Review of European Studies, 9(3). https://doi.org/10.5539/res.v9n3p8

Cossiga, G. A. (2017). The instability of the economy pre-financial crisis. Some considerations on the Phillips curve: it's still reliable. Journal of Management Studies.

Dickey, D., \& Fuller, W. (1979). Distribution of the Estimators for Autoregressive Time Wayne Fuller Series with an Unit Root. Journal of American Statistical Association. 
Dornbusch, R., \& Fischer, S. (1993). Moderate Inflation. World Bank Economic Review, 7, 1-44. https://doi.org/10.1093/wber/7.1.1

Friedman, M. (2007). On economics - Selected Papers. University of Chicago Press.

Geithner, T. F. (2015). STRESS TEST - Reflections on Financial Crises - RH Business Books.

IMF - International Financial Statistics - Database, various years.

Inquiry Report. (2011). THE FINANCIAL CRISIS - Final Report of the National Commission on the Causes of the Financial and Economic Crisis in the United States - Official Edition.

Kindleberger, C. (1973). The World in Depression: 1929-1939. University of California Press

Krugman, P. R. (2000). Thinking about the liquidity trap. Journal of the Japanese and International Economies. https://doi.org/10.1006/jjie.2000.0458

Krugman, P. R. (2009). The return of depression economics and the crisis 2008. W.W. Norton \& Company, New York.

Krugman, P. R. (2012). End This Depression Now - W.W. Norton \& Company, Inc. New York.

Lindberg, L. N., Maier, S., \& Barry, B. (1985). The Politics of Inflation and Economic Stagnation theoretical approaches and international case studies. - Brookings Institution Washington D.C.

Mirrlees, J. A. (2006). Welfare, Incentives, and Taxation. Oxford University Press. https://doi.org/10.1093/acprof:oso/9780198295211.001.0001

OECD. Stat - Database, various years.

Raines, J. P., \& Leathers, C. G. (2008). Debt, Innovation and Deflation: The Theories of Weblen, Fisher, Schumpeter and Minsky - Edward. Elgar Publishing.

Reinhart, C., \& Rogoff, K. S. (2009). The Time Is Different - Eight Centuries of Financial Folly. Princeton- University Press - Princeton and Oxford.

Roach, S. S. (2009). The next Asia- Opportunities and challenges for a new globalization. John Wiley \& Sons.

Roubini, N., \& Mihm, S. (2011). Crisis Economics: A crash Course in the Future of Finance. Paperback.

Roubini, N., Alesina, A., \& Cohen, G. (1997). Political Cycles and the Macroeconomy. MIT Press.

Sargent, T. J. (1982). The Ends of Four Big Inflation. In Inflation: Causes and Effect - University of Chicago Press Robert Hall Editor.

Schumpeter, J. (1939). Business Cycles: A theoretical, historical and statistical analysis of the Capitalist process McGraw-Hill Book Company

Shilling, A. G. (2001). Deflation. How survive and thrive in coming wave of deflation. Paperback

Stiglitz, J. E. (2016). The EURO. How the common money threatens the future of Europe. W. W. Norton \& Company New York-London

Stock, J. H., \& Watson, M. W. (1993). A simple estimator of cointegrating vectors in higher order integrated systems. Econometrica: Journal of the Econometric Society. https://doi.org/10.2307/2951763

Temin, P. (1989). Lessons from the Great Depression. The MIT Press - Cambridge, Massachusetts.

Wapshott, N. (2011). KEYNES - HAYEK. The Clash that Defined Modern Economics. W. W. Norton \& Company - New York-London.

\section{Copyrights}

Copyright for this article is retained by the author(s), with first publication rights granted to the journal.

This is an open-access article distributed under the terms and conditions of the Creative Commons Attribution license which permits unrestricted use, distribution, and reproduction in any medium, provided the original work is properly cited. 